\title{
Determine Entrepreneurial Characteristics Using Mobile Android Gamer Freezer
}

\author{
https://doi.org/10.3991/ijim.v12i1.7790 \\ Mohammad Ismail $\left({ }^{\varpi}\right)$, Ahmad Fuad Ibrahim, Mohd Rafi Yaacob, \\ Asrul Hey Ibrahim, Mohd Nazri Zakaria, Razli Che Razak, \\ Mohd Nor Hakimin Yusoff, Tan Tse Guan, Anis Nabila Kamaruddin \\ Universiti Malaysia Kelantan, Malaysia \\ mohammad.i@umk. edu.my
}

\begin{abstract}
Psychometric Test has been used as an individual trait measurement for a long time for both experienced entrepreneurs as well as young generation who are looking for their potential in entrepreneurship. The assessment and measurement of strength and weaknesses of key entrepreneurial traits provides the entrepreneurial level and personal development planning for entrepreneur or those who want to venture into business. However, the traditional psychometric test lacks of fun element which is less enjoyable activity during answering the test. Furthermore, it requires basic understanding of business jargon that difficult for certain respondents to provide accurate respond. The purpose of this study is to propose a gamification approach which is mobile game application called 'Freezer' that can measured entrepreneurial traits of the player. In this sense, 'Freezer' creates a simulated scenario for respondents to play as an ice cream business owner and to win as a successful business person, each action done will be measured as entrepreneurial traits criteria. At the end of the game, the result will be presented that can describe the entrepreneurial characteristics of the individuals based on their planning and activities during playing the game.
\end{abstract}

Keywords-Mobile android, entrepreneurial characteristic, psychometric test, gamification

\section{Introduction}

The need of determining people characteristic is considered important particularly for identifying the entrepreneurial characteristic of the individual in any organization. The evaluation of people characteristic is essential in every section of any organization in order to develop the human talent. Intangible people value can be measured in various aspects and one of the important aspects is human psychology. Psychological testing in its modern form is originated in laboratory studies of sensory discrimination, motor skills, and reaction time by Francis Galton (1822-1911) [1]. Psychometrics is a field of study concerned with the theory and technique of psychological measurement that being assigned to test, measure, assess, and related activities. Part 
of the field is to measure the abilities, attitudes, personality traits, skills and knowledge, and educational achievement. There are lots of approach-in determining and measuring personality.

Entrepreneurial characteristics measurement is one aspect of personality testing where the psychometric profile of a respondent is tabulated based on pre-defined individual traits. Perceived psychology of entrepreneurs is often founded in media rhetoric rather than data-driven scientific enquiry [2]. This can lead to a disconnection between the potential of entrepreneurship and the political, financial and regulatory conditions in which it is often exercised. Psychometric profiling to approach had been demonstrated result with empirical study in various sector of business. However, the obvious disadvantages of psychometric method are; lack of enjoyment in the process of evaluation and answering the questionnaire, and measurement based on respondent assumption rather than actual action. In order to address these two concerns, using gamification concept may help to develop enjoyment in the evaluation process when respondent answer the questionnaire. By using gamification approach it will to measure respondent action rather than personal assumption.

In order to empirically to investigate individual differences in entrepreneurial characteristic, mobile android game (Freezer) is developed as an alternative of a traditional psychometric test. Furthermore, to help aspiring entrepreneurs to evaluate their entrepreneurial characteristic, an innovative mobile android game (Freezer) based on entrepreneurship has been designed. This new alternative approach help to simplify the evaluation process, effortless, and similarly important as a new approach to measure entrepreneurial characteristic. The used of mobile android game (Freezer) are expected to have more accurate measure of entrepreneurial traits compare to ordinary psychometric test where traits are measures based on actual action. It is also can act as another validation of paper based psychometric test.

\section{Gamification Concept}

Generally, gamification is the application of game-design fundamentals and game principles in non-game settings to improve user engagement, organizational productivity, flow, learning, employee recruitment and evaluation, ease of use, usefulness of systems, physical exercise and others [3]. A collection of research on gamification shows that most of the studies on gamification demonstrate has positive effects on individuals [4]. Gamification can also develop an individual's aptitude for comprehension digital content and recognize a certain area of study.

The gamification techniques are proposed to influence people's natural needs for socializing, learning, mastery, competitiveness, accomplishment, status, assertiveness, altruism, or simply their response to the enclosing of circumstances as game or play [5]. Another approach from gamification is to create accessible tasks feel more like games. Certain techniques used in this approach include consequential choice of boarding with a tutorial, increasing challenge and adding storyline [6]. Using the gamification concept for measuring entrepreneurial traits may increase the interest in using the tools especially for young generation. Gamification concept may help to 
measure entrepreneurial characteristics indirect way so that it will generate better result and free of bias.

\section{Characteristics of Successful Entrepreneurs}

Personality variables have a significant role in developing theories of the entrepreneurial process areas such as entrepreneurial career intentions, entrepreneurial assessment and opportunity recognition, entrepreneurial role inspiration, and new venture survival. According to [7], it is significant differences between entrepreneurs and managers on personality characteristic which determine the importance of certain characteristics in supporting a successful entrepreneur.

In this research, McClelland's findings on characteristics of a successful entrepreneur have been used as the 'Freezer' rule of items to be measured. McClelland listed nine competencies which are significantly more characteristic of successful rather than average entrepreneurs [8]. Definitions of the entrepreneurial traits are as follows:

1. Initiative - Doing things before being asked or involuntary to do something by events.

2. Assertiveness - Encounters problems with others instantaneously. Tells substitute what they need to do.

3. Sees and acts on opportunities - Take advantage of unusual opportunities to launch a new business, procures financing; land, work space, or assistance.

4. Efficiency orientation - Explores for or discovers ways to organize things faster or at less expense.

5. Concern for high quality of work - States an interest to produce or sell with betterquality product or service.

6. Systematic planning - Breaks a large task down into subtasks, or sub-goals, anticipates obstacles, evaluates alternatives.

7. Monitoring - Increases or handles procedures to ensure that work is accomplished or that effort meets standards of quality.

8. Commitment to work contract - Makes an own sacrifice or expends particular determination to accomplish a job, pitches in with workforces or works in their place to get the job done.

9. Recognizing the importance of business relationship - Take action to create friendly relationships with consumers, sees interactive relationships as a fundamental business resource, places long-term good will over short-term gain.

Each of these traits is then mapped on to the player action in the 'Freezer' during game play and proper marks are given tabulation at the end of game or at any time within the game session. The concept of achievement motivation was developed by David McClelland and forms a central theoretical construct in the literature on entrepreneurship [8]. In the context of the present research, achievement motivation regarded as an underlying personality trait that is expressed behaviourally through competencies in the achievement cluster, such as initiative, sees and acts on opportunities, concern for high quality of work, commitment to work contract, and efficiency orien- 
tation. According to [9] the achievement motivation can be used to predict the need for achievement theory proposed by McCelland (1961), which explains that individuals have an innate desire to succeed, accomplish, thrive and achieve. Entrepreneurs with high levels of need for achievement typically try to set difficult goals for themselves and intend to achieve these goals, they are enthusiastic and they seek selfdevelopment [10]. Furthermore, entrepreneurs with a high level of need for achievement have a strong desire to solve problems by themselves, they like setting and achieving goals and they enjoy receiving feedback on their achievements [11].

\section{$4 \quad$ Freezer Game Application Implementation}

'Freezer' is a mobile game application built for the Android platform with the main objective to providing an alternative method to measure entrepreneurial traits compared to traditional psychometric test. 'Freezer' takes the measurement rules from the psychometric test and used the gamification concept as the medium to be used by respondents with a business simulation approach.

\subsection{Gameplay and Game Mechanic}

In 'Freezer', a player will be given 5-10 minutes of play time before the game ends and calculated results will be shown at the end of the game. The main reasons to set time limitation are to force player to do what they think the most important task to be done as entrepreneur. Using this approach, 'Freezer' will help to describe which traits more dominant compare to others. As the game start, player needs to choose their character. This simple feature of the game gives a sense of belonging and attachment to the main character and game storyline to a player. Once the character has been chosen, the game screen then bring the player to flea market site that marked with potential site for stall booth rental. Each location is ranked based on the number of stars where higher numbers of stars indicate a more strategic location and higher chances of getting customers. Figure 1 below shows the initial start-up screen of the game where the main character in the middle and the user interface is at the top and bottom of the game screen.

The Freezer game mechanics use two gesture controls which are tap and drag. Tapping on a button and site will bring the player into a deeper game overlays instruction or button event and the drag character will be assigned the tasks such as taking care of a stall, marketing activities, training, etc. Furthermore, the objective of the Freezer game play is to expand the ice cream stall business and to generate maximum income out of it. Even though the game's objective is to make money, the entrepreneurial traits measurement does not consider revenue as one of the performance criteria. 


\subsection{Initiative trait action}

As described in section 4, the initiative trait measures the mind-set of entrepreneurs to do something proactively. In Freezer, each time payment is settled within the allocated time, the initiative mark will increase. Figure 2 shows the warning sign when payment (staff salary and supplier invoice) is not paid within the allocated duration. Once this happens, the initiative mark will decrease.

Another action that increases initiative mark is when player initiate marketing activities to attract customer to visit their ice cream stall. Figure 3 shows option of marketing activities that can be assigned to staff.

\subsection{Assertiveness trait action}

From time to time, there will be random event pop-up on the screen that requires response and fast decision by the player. Each of these events is designed to measure traits based on response from player to the scenario. Assertiveness traits measure events such as staff discipline issues, supplier problem, or customer complaint.

\subsection{Sees and acts on opportunities trait action}

Opportunities to expand the business come in various scenarios. One of them is by choosing a high potential site to gain more customer access. This can be done by tapping on any empty site and starting a new rental site. Figure 4 shows the overlay for renting a new stall and expanding the business further. Other marks on this trait come from opportunities in new investments of random event generators.

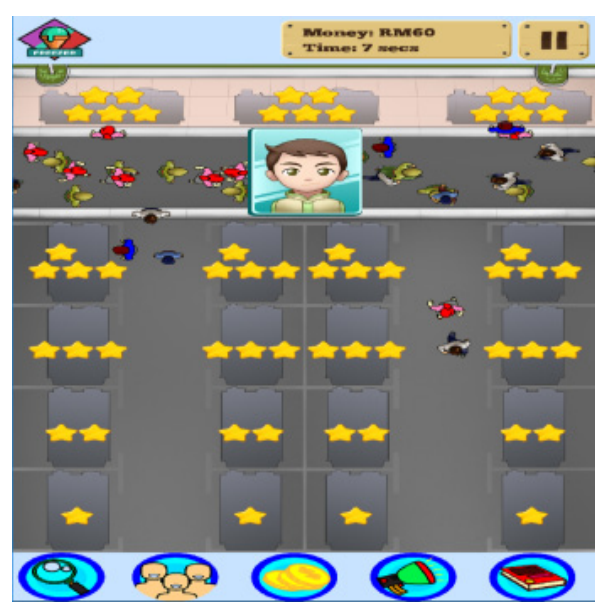

Fig. 1. Initial Freezer Game Screen

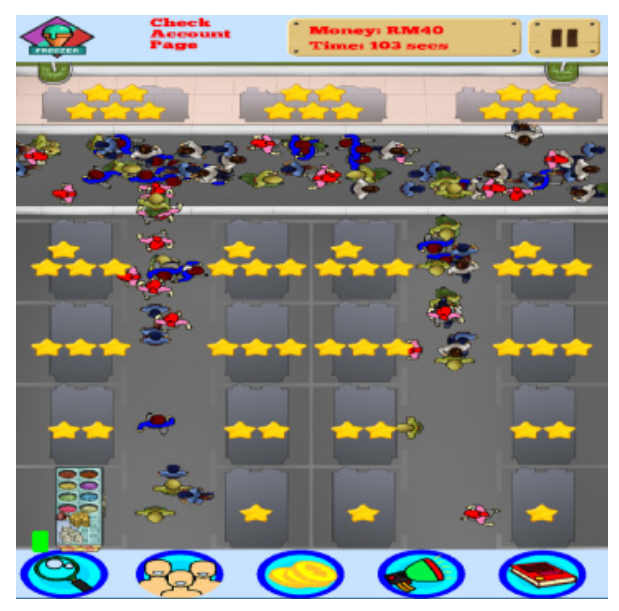

Fig. 2. Warning message on payment overdue 


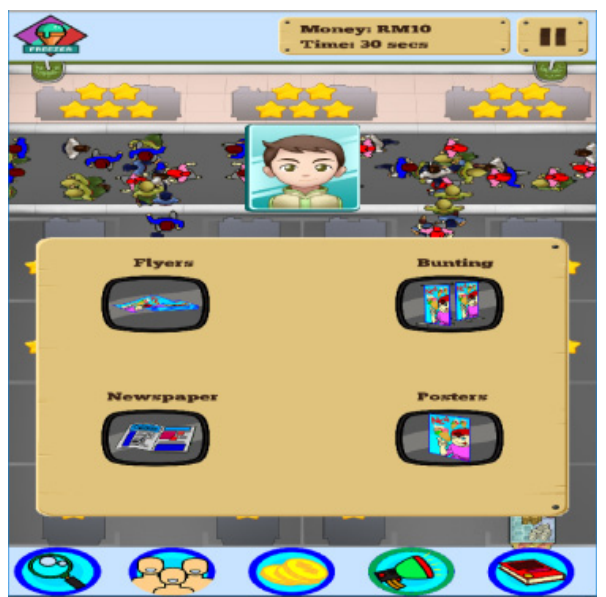

Fig. 3. Marketing overlay selection

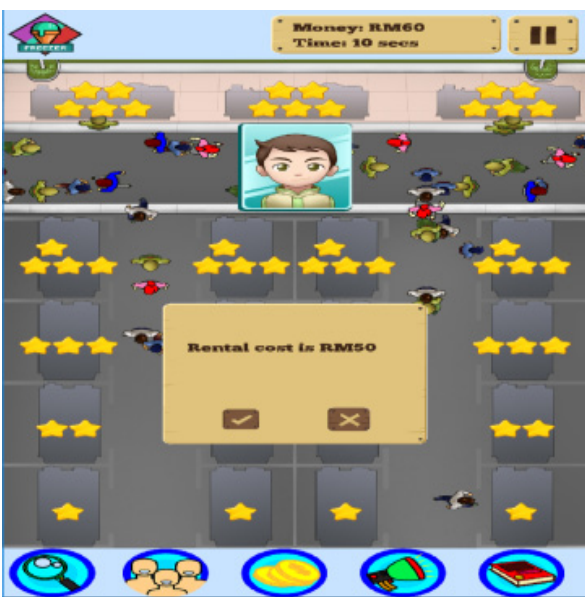

Fig. 4. New stall site rental overlay

\subsection{Efficiency orientation trait action}

Efficiency mark measures are based on how well a player handles the staff and materials. More idling time by staff and longer material turn around duration will reduce the mark on the efficiency trait. Unattended customers will also reduce the efficiency mark since it is considered a loss of potential income due to inefficient manpower handling. To balance more jobs, the player needs to hire new staff and assign the jobs accordingly. Figure 5 shows the overlay to hire new staff.

\subsection{Concern for high quality of work trait action}

Desire to produce or sell a top or better-quality product or service can be represented by effort to research a new product. Players can start research for better products by tapping on the research button at the bottom left of the game screen. This will bring up a new product research overlay and players can select a new item to research. Next step is to assign a staff to do the research and to allocate a suitable supplier for this new product.

Another action that portrays eagerness of the player to provide the best service to customers is by sending his/her staff to be trained in selling skills. This indicates effort by the player to increase the quality of the customer service. Players can start staff training by tapping on the training button at the bottom right of the game screen. This will bring up the staff training overlay and players can select the skill that needs to be trained. 


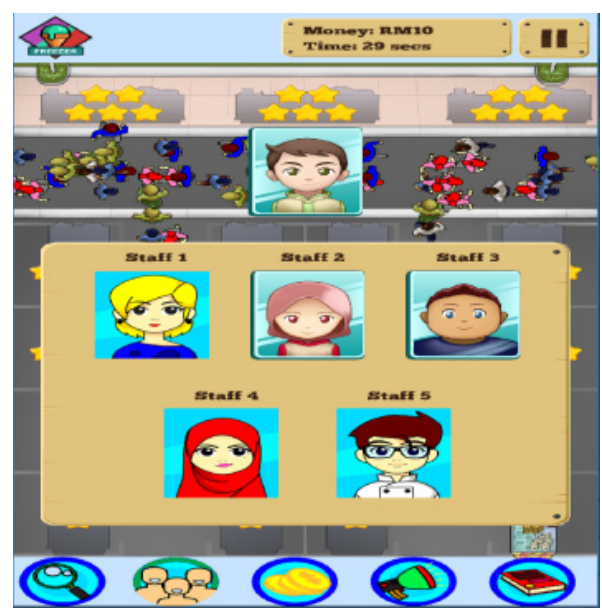

Fig. 5. Hiring new staff overlay

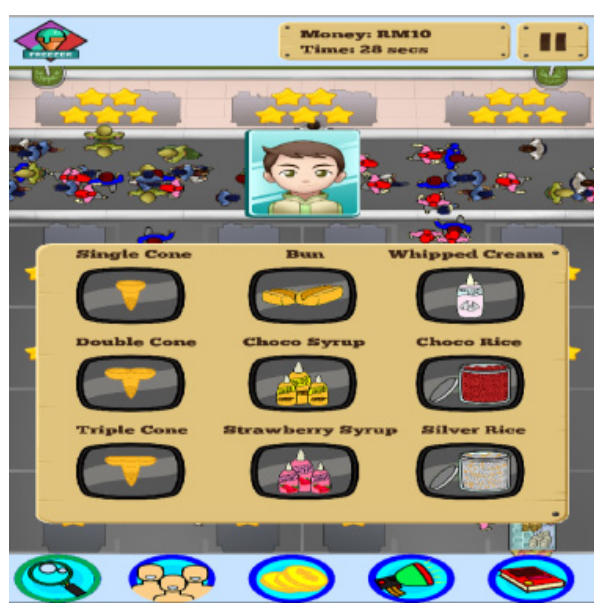

Fig. 6. New product research overlay

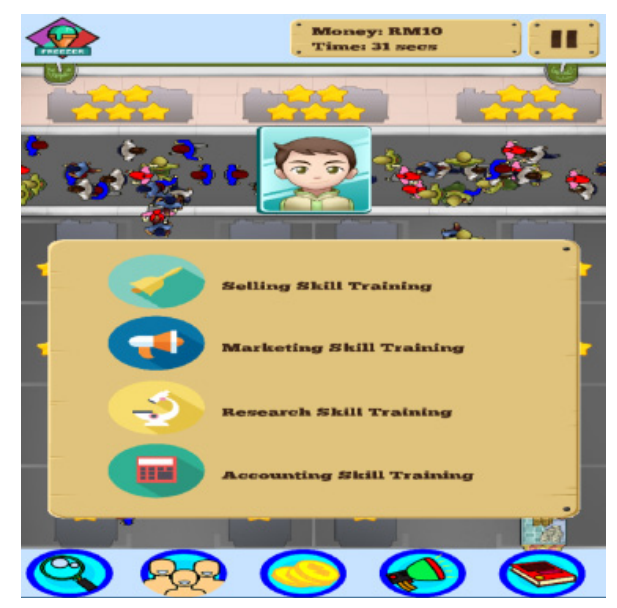

Fig. 7. Staff training overlay

\subsection{Systematic planning trait action}

Systematic planning trait will be handled by a random event. Systematic planning trait measures events such as getting a big order for an external occasion whereby players need to respond to staff planning and job delegation to handle the big order and attend to customer needs.

\subsection{Monitoring trait action}

Monitoring trait will get marks when the player starts sending his/her staff for documentation related training such as accounting training. This trait will also be handled 
by a random event. Monitoring trait measures event such as documented procedure requirement, customer complaint filing, material tracking, etc.

\subsection{Commitment to work contract trait action}

Commitment to work contract trait will get marks when a player's character assigns a staff enabled job. In Freezer, some of the tasks such as staff hiring and payment can be done by the main character. This job is disabled for the staff. Each time the main character do normal jobs, a small weight of marks will be added to the commitment to work contract trait. This trait will also be handled by a random event. Commitment to work contract includes events such as customer requests money back, supplier payment term issue, etc.

\subsection{Recognize the importance of business relationship trait action}

Recognize the importance of business relationship trait will get marks when the player's character is assigned to a business networking session and rewards staff action. Figure 8 shows the accounting overlay where a player can spend money to reward his/her staff and have business networking sessions. This trait will also be handled by a random event. Recognizing the importance of business relationship includes event such as support customer request, handle staff issue with fair judgement, etc.

\subsection{Game result and focus point}

At any time of the game player can pause time by tapping to pause button at the top right of the game screen. Once menu overlays drop down from top screen, player can display result by tapping on result button. Figure 9 shows game results overlay. The result will be automatically appeared once game is completed. Apart from nine entrepreneurial traits, there is additional mark to be measured. This mark will be reduced each time player do something without understand the job impact for example attempt to spend money on certain activity but receive cash/payment is not enough and indicate player understand what his/her action rather than just tapping and dragging around without proper objective.

\section{Conclusion}

'Freezer' is a mobile game application which utilizes the psychometric personality testing method but developed by using a gaming approach instead of a paper based questionnaire. 'Freezer' game plays use business simulation to create scenario events to trigger action from the player. 'Freezer' can be used by organizations, schools, universities and colleges, for training and development, and for personal growth to measure an individual's aptitude on entrepreneurship. 'Freezer' can provide an analysis of the entrepreneurial traits' strengths and weaknesses; therefore, the user can make a better decision on personal improvement and future entrepreneurial ventures. 


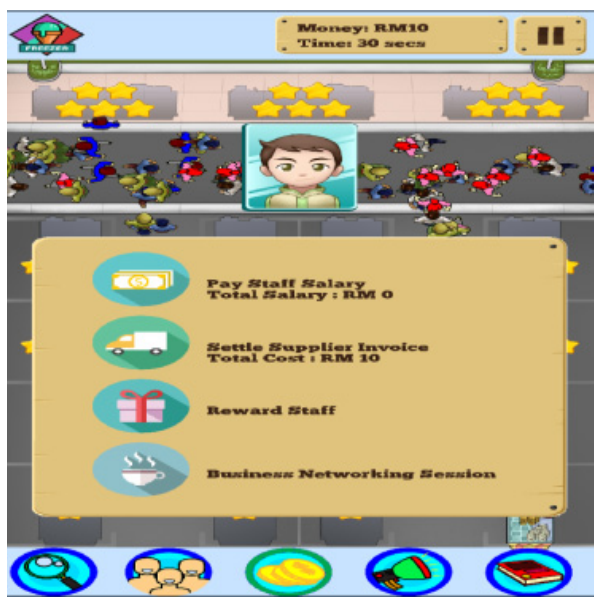

Fig. 8. Accounting overlay

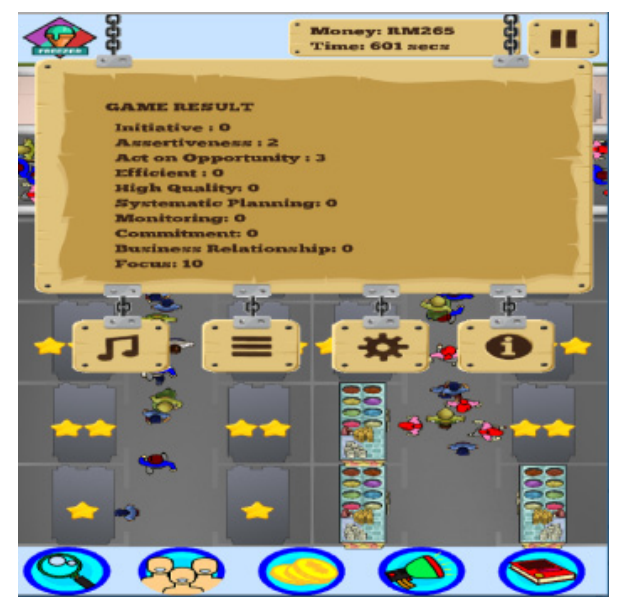

Fig. 9. Game result overlay

In order for the 'Freezer' mobile game application to be used widely, future research may look on further validation for respondents from different backgrounds to make sure 'Freezer' can be used by any age group. Interface for 'Freezer' needs further improvement to be more intuitive with less time spent for first time users in understanding the game's mechanics.

\section{Acknowledgment}

This research was funded by University Malaysia Kelantan, Malaysia. (R/MyRA/A01.00/01137A/002/2016/000387).

\section{$7 \quad$ References}

[1] Robert J. Gregory, Wheaton College (2004).” Psychological Testing: History, Principles, and Applications, $4^{\text {th }}$ Edition," 1-13.

[2] Barclays Bank PLC \& The Psychometrics Centre, University of Cambridge (2015). "The psychology of entrepreneurship: A data driven study into the motivation behind new business creation," 1-32.

[3] Lieberoth, A. (2015). "Shallow Gamification, Testing Psychological Effects of Framing an Activity as a Game, Games and Culture,"10( 3), pp. 229 - 248 https://doi.org/10.1177/1555412014559978

[4] Byron Reeves; J. Leighton Read (2009). "Total Engagement: Using Games and Virtual Worlds to Change the Way People Work and Businesses Compete," Harvard Business Press. p. 177

[5] Greenblat, Cathy Stein (1988). "Designing Games and Simulations: An Illustrated Handbook", Sage Publications, Newbury Park.

[6] Elgood, Chris (1996). "Using Management Games. 2nd edition, Gower Press", Aldershot, Hampshire, England 
[7] Hao Zhao \& Scott E. Seibert (2006). "The Big Five Personality Dimensions and Entrepreneurial Status: A Meta-Analytical Review," Journal of Applied Psychology, 91 (2), 259 271. https://doi.org/10.1037/0021-9010.91.2.259

[8] David C. McClelland \& McBer and Co (1986). "Characteristics of Successful Entrepreneurs", Third Creativity, Innovation and Entrepreneurship Symposium held in Framingham, MA.

[9] Bird, B. (1989). "Entrepreneurial Behavior". Glenview, IL: Scott, Foresman and Company

[10] Fine, S., Meng, H., Feldman, G. \& Nevo, B. (2012). "Psychological predictors of successful entrepreneurship in China": An empirical study. International Journal of Management, 29/2(1), 279- 292.

[11] Dollinger, M., 1995. "Entrepreneurship: Strategies and Resources”. Illinois: Irwin

\section{Authors}

Mohammad Ismail is with the Faculty of Entrepreneurship and Business Universiti Malaysia Kelantan (UMK) Malaysia, Locked Bag 36, Pengkalan Chepa, 16100 Kota Bharu Kelantan.

Mohd Rafi Yaacob is with the Faculty of Entrepreneurship and Business Universiti Malaysia Kelantan (UMK) Malaysia, Locked Bag 36, Pengkalan Chepa, 16100 Kota Bharu Kelantan.

Asrul Hey Ibrahim is with the Faculty of Entrepreneurship and Business Universiti Malaysia Kelantan (UMK) Malaysia, Locked Bag 36, Pengkalan Chepa, 16100 Kota Bharu Kelantan.

Mohd Nazri Zakaria is with the Faculty of Entrepreneurship and Business Universiti Malaysia Kelantan (UMK) Malaysia, Locked Bag 36, Pengkalan Chepa, 16100 Kota Bharu Kelantan.

Razli Che Razak is with Entrepreneurship Institute (UMK-EI) Universiti Malaysia Kelantan (UMK) Malaysia, Locked Bag 36, Pengkalan Chepa, 16100 Kota Bharu Kelantan.

Mohd Nor Hakimin Yusoff is with Institute Of Small And Medium Enterprises (ISME) Universiti Malaysia Kelantan (UMK) Malaysia, Locked Bag 36, Pengkalan Chepa, 16100 Kota Bharu Kelantan.

Tan Tse Guan is with the Faculty of Creative Technology and Heritage Universiti Malaysia Kelantan (UMK) Malaysia, Locked Bag 36, Pengkalan Chepa, 16100 Kota Bharu Kelantan.

Ahmad Fuad Ibrahim is a PhD Student at Faculty of Entrepreneurship and Business, Universiti Malaysia Kelantan (UMK) Malaysia, Locked Bag 36, Pengkalan Chepa, 16100 Kota Bharu Kelantan.

Anis Nabila Kamaruddin is a Master Student at Faculty of Entrepreneurship and Business, Universiti Malaysia Kelantan (UMK) Malaysia, Locked Bag 36, Pengkalan Chepa, 16100 Kota Bharu Kelantan. 